\title{
Credit Risk Assessment of Finance-transportation and Warehouse Financing Model
}

\author{
Ruan Jian ${ }^{1}$ Cai Minrong ${ }^{2, *}$ \\ ${ }^{1}$ School of Finance and Investment, Guangdong University of Finance, Guangzhou, 510521, China \\ ${ }^{2}$ School of Business Administration, Guangdong University of Finance, Guangzhou, 510521, China \\ *Corresponding author. Email: cmr@gduf.edu.cn
}

\begin{abstract}
Based on the sample of 60 manufacturing listed companies (included 20 Special treatment companies and *Special treatment companies), a credit risk assessment index system is built by principal component analysis. The default of financing companies is predicted based logistic regression analysis. The result shows that the prediction accuracy of credit risk assessment on third-party logistics and pledge characteristics is improved, which provides the decision basis for commercial bank financing.
\end{abstract}

Keywords: Supply Chain Finance, Finance-transportation and Warehouse, Credit Risk, Logistic, Principal component analysis.

\section{INTRODUCTION}

Compared with large enterprises, small and mediumsized enterprises (SMEs) are more difficult to finance because of high default probability. The financing difficulties have affected the development of enterprises. Finance-transportation and warehouse (FTW) Financing is an important financing channel for SMEs. The financing SMEs sign an agreement with the third-party logistics enterprises (3PL) to store the inventory or current assets as pledges at the designated warehouse of the logistics company. The financing SMEs apply for loans to commercial banks by the warehouse receipt certificates from the 3PL. FTW combines the professional resources of financial institutions, enterprises and 3PL organically and allocates them as a whole, which can effectively alleviate the financing problems in production and circulation, and significantly expand the credit business of financial institutions.

In the literature review, we learned that some scholars have discussed the issues of financing model in supply chain management (Klapper, 2004[1]), and explained the meaning and service function of FTW (Luo, 2002[2]). For the empirical study of credit risk, credit risk assessment system was built by considering subject rating and debt rating (Xiong, 2009[3]) and support vector machine (SVM) (Hu, 2011[4]). By using the case analysis method, the 3PL supply chain financing mode were analyzed, and carried out the simulation by using the system dynamics method Analysis (shao, 2021[5]).

Due to China's credit environment and insufficient data accumulation, most of the researches are qualitative research, and there are few research results on measurement models and empirical analysis. In this paper, we extract financial data from listed companies in China, establish a credit risk assessment system for FTW financing, use principal component analysis to extract principal components, then use logistic to perform regression analysis, and finally integrate these two methods to conduct credit risk assessment.

\section{CREDIT RISK ASSESSMENT SYSTEM OF FTW FINANCING}

\subsection{The Influencing Factors of Credit Risk}

\subsubsection{Influencing Factors of SMEs}

Comprehensive strength of SMEs is the emphasis of Credit risk assessment. We measure the financial situation and sustainable development capabilities of enterprises from solvency, profitability, operation capability and development capability. 


\subsubsection{Influencing Factors of $3 P L$}

In the mode FTW Financing. 3PL are responsible for Guaranteeing and supervising. The data authenticity of the 3PL, the appropriateness of monitoring procedure, and the condition of inventory, are the influencing factors of credit risk.

\subsubsection{Influencing Factors of Pledge}

The main role of pledge is to prevent SMEs from defaulting. The 3PLs are in charge of managing the inventory, so it is necessary to consider the impact from the Inventory Turnover characteristics of pledges and price fluctuations on credit risk.

\subsection{Credit risk Assessment index system}

Based on the existing research, we measure the Enterprise's comprehensive strength of SMEs from the profitability, solvency, operational capacity and development capacity. Based on profitability, solvency and enterprise status, we measure the comprehensive quality of 3PL. The characteristics of pledges are measured from the price and market characteristics. Finally, we build a three-levels credit risk assessment index system included 17 indexes (see Table 1).

Table 1. Credit risk assessment index for FTW

\begin{tabular}{|c|c|c|c|c|}
\hline First-level index & Second-level index & Third-level index & Index description & Variable \\
\hline \multirow{10}{*}{$\begin{array}{l}\text { Comprehensive } \\
\text { quality of small } \\
\text { and medium } \\
\text { sized enterprises }\end{array}$} & \multirow{2}{*}{ Profitability } & Ratio of income as sales & net profit / sales revenue & L1 \\
\hline & & Return on Equity & net income / shareholders' equity & $\mathrm{L} 2$ \\
\hline & \multirow{4}{*}{ Debt-paying ability } & Current Ratio & current assets / current liabilities & L3 \\
\hline & & Quick Ratio & $\begin{array}{l}\text { (current assets-inventory) / current } \\
\text { liabilities }\end{array}$ & L4 \\
\hline & & Debt-to-asset ratio & total debt / total assets & L5 \\
\hline & & Interest coverage ratio & $\begin{array}{l}\text { profits before interest and tax / interest } \\
\text { expenses }\end{array}$ & L6 \\
\hline & \multirow[t]{2}{*}{ Operation Capability } & Current Assets Turnover & $\begin{array}{l}\text { total sales / ((beginning assets + ending } \\
\text { assets) / 2) }\end{array}$ & L7 \\
\hline & & Inventory turnover ratio & sales revenue / average inventory & L8 \\
\hline & \multirow{2}{*}{$\begin{array}{l}\text { Development } \\
\text { Capability }\end{array}$} & Sales growth rate & $\begin{array}{l}\text { (current period sales - prior period sales) } \\
\text { / prior period sales }\end{array}$ & L9 \\
\hline & & Net profit growth rate & $\begin{array}{l}\text { (current period net profit - prior period } \\
\text { net profit) / prior period net profit }\end{array}$ & L10 \\
\hline \multirow{5}{*}{$\begin{array}{l}\text { Comprehensive } \\
\text { quality of 3PL }\end{array}$} & Profitability & Ratio of income as sales & net profit / sales revenue & V1 \\
\hline & Debt-paying ability & Debt-to-asset ratio & total debt/total assets & $\mathrm{V} 2$ \\
\hline & \multirow{3}{*}{ Enterprise status } & Market growth rate & market growth rate of the year & $\mathrm{V} 3$ \\
\hline & & Regional market share & market share of the year & V4 \\
\hline & & Enterprise scale & number of employees of the year & V5 \\
\hline \multirow{2}{*}{$\begin{array}{l}\text { Characteristics } \\
\text { of pledge }\end{array}$} & Price stability & Price fluctuation & $\begin{array}{l}\text { price fluctuation of pledge in recent } \\
\text { three month }\end{array}$ & S1 \\
\hline & Market characteristics & Product life cycle & in which life cycle the product is & $\mathrm{S} 2$ \\
\hline
\end{tabular}

\section{DATA, MODEL AND RESULTS}

\subsection{Data source and processing}

The data of this paper are mainly from 2019 China Stock Market \& Accounting Research (CSMAR) Database. We select 60 companies from hundreds of manufacturing SMEs listed companies randomly, included 20 Special treatment (ST) listed and *ST listed companies with high credit risks, and 40 companies with medium risk. The credit risk is determined by the probability of default, that is, the higher probability of default, the higher the credit risk. The characteristics of pledges are key factors to credit risk assessment. However, the characteristics of pledges are difficult to be measured by relevant financial indexes. As shown in Table 2, we apply scoring criteria of qualitative indexes instead.
Table 2. Qualitative index score

\begin{tabular}{|l|l|l|}
\hline Variable & Description & Score \\
\hline S1 & $\begin{array}{l}\text { price fluctuation } \\
\text { of pledge in } \\
\text { recent 3 month }\end{array}$ & $\begin{array}{l}\text { The smaller the fluctuation of } \\
\text { the pledge price, the higher } \\
\text { the index score (0-1 score) }\end{array}$ \\
\hline S2 & $\begin{array}{l}\text { in which life } \\
\text { cycle } \\
\text { product is }\end{array}$ & $\begin{array}{l}1 \text { score for mature stage; } 0.7 \\
\text { score for growth stage; 0.4 } \\
\text { score for early stage; 0 score } \\
\text { for decline stage }\end{array}$ \\
\hline
\end{tabular}

\subsection{Principal component extraction of assessment indexes}

Before the principal component extraction, we analyze the correlation between financial indicators. Correlation analysis shows that the correlation coefficients between most financial indicators is not significant. Construct vector $L=\left(L_{1}, L_{2} \cdots+L_{n}\right)$ of $n$ 
indicators. By calculating the new principal component indexes, the equation is as follows:

$$
\left\{\begin{array}{l}
F_{1}=\alpha_{11} \cdot L_{1}+\alpha_{12} \cdot L_{2}+\cdots+\alpha_{1 n} \cdot L_{n} \\
F_{2}=\alpha_{21} \cdot L_{1}+\alpha_{22} \cdot L_{2}+\cdots+\alpha_{2 n} \cdot L_{n} \\
\cdots \\
F_{m}=\alpha_{m 1} \cdot L_{1}+\alpha_{m 2} \cdot L_{2}+\cdots+\alpha_{m n} \cdot L_{n}
\end{array}\right.
$$

Firstly, KMO \& Bartlett test, show that KMO is greater than 0.6 and significant at $5 \%$ significance level, which indelicate Principal Component Analysis is valid.

Secondly, the principal component analysis of the samples is carried out. Combined with the scree plot (see Table 3) and the total sum of square (see Figure 1), five principal components that can be used to explain $88.6 \%$ of the original variables are selected.

Table 3. Rotation sums of squared loadings

\begin{tabular}{|l|l|l|l|}
\hline & Total & \%of Variance & Cumulative \% \\
\hline 1 & 4.334 & 36.115 & 36.115 \\
\hline 2 & 3.008 & 25.069 & 61.184 \\
\hline 3 & 1.948 & 16.232 & 77.416 \\
\hline 4 & 1.641 & 11.209 & 82.511 \\
\hline 5 & 1.580 & 9.647 & 88.625 \\
\hline
\end{tabular}

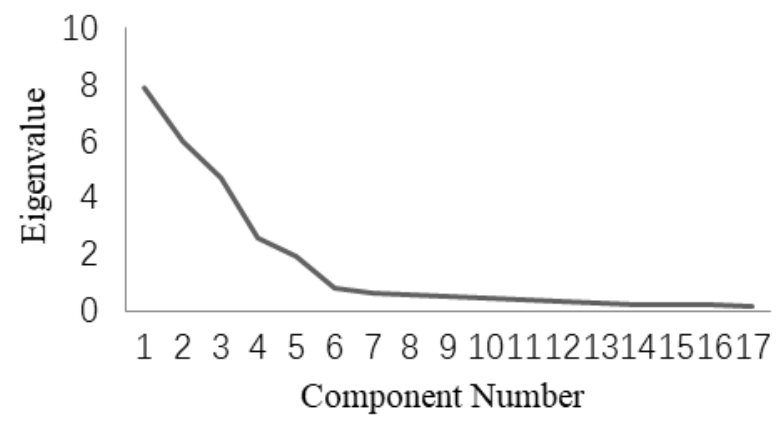

Figure 1 scree plot

The sample data are converged by 25 iterations to obtain the rotation component matrix, and the expression of five principal components is as follow:

$$
F_{i}=\alpha_{i 1} \cdot Z L_{1}+\alpha_{i 2} \cdot Z L_{2}+\cdots+\alpha_{i 17} \cdot Z L_{17}
$$

$\alpha_{\text {in }}$ represents the $i$-th coefficient corresponding to the standardized variable $Z L_{n}$ in the matrix. The information from $Z L_{3} \square Z L_{8}$ are mainly covered by $F_{1}$, which represents the solvency and operational capacity of SMEs. The information of $Z L_{1} 、 Z L_{2}$ 、 $Z L_{9}$ and $Z L_{10}$ are mainly covered by $F_{2}$, which indicates the development ability and profitability of SMEs. The information of $Z V_{1}$ and $Z V_{2}$ are mainly covered by $F_{3}$, which characterize the 3PL financial capacity. $F_{4}$ covers $Z V_{3} \square Z V_{5}$, which represents the size and market position of the 3PL. $F_{5}$ covers $Z V_{3} \square Z V_{5}$, which is demonstrated by the characteristics of pledge.

\subsection{Logistic Regression Analysis}

The credit risk of an enterprise depends on the enterprise defaults. Let 1 indicates that the enterprise will default, and 0 indicates that the enterprise will not default. The mathematical expressions of SMEs default probability is given by

$$
\log i t(P \mid W=\text { default })=\ln (w / 1-w), w \in[0,1]
$$

The multi-variable Logistic regression model is

$$
\ln (w / 1-w)=\alpha_{0}+\alpha_{1} \cdot F_{1}+\cdots \alpha_{5} \cdot F_{5}
$$

where $\alpha$ is the coefficient of Principal component variable, The larger the value of $W$, the higher the probability of default and the higher the credit risk of the enterprises. By combining Equation (3) and (4), the mathematical expressions of default probability is

$$
W=\frac{e^{\alpha_{0}+\alpha_{1} \cdot F_{1}+\cdots \alpha_{5} \cdot F_{5}}}{1+e^{\alpha_{0}+\alpha_{1} \cdot F_{1}+\cdots \alpha_{5} \cdot F_{5}}}
$$

The four principal components are extracted by principal component analysis. By Logistic Regression analysis, the expression of enterprise default probability is

$$
\begin{aligned}
& \ln (w / 1-w)=-2.134+2.061 \times F_{1}+1.745 \times F_{2} \\
& +2.512 \times F_{3}+4.021 \times F_{4}+3.801 \times F_{5}
\end{aligned}
$$

The probability of default in Credit risk Assessment index system is

$$
W=\frac{e^{-2.134+2.061 \times F_{1}+1.745 \times F_{2}+2.512 \times F_{3}+4.021 \times F_{4}+3.801 \times F_{5}}}{1+e^{-2.134+2.061 \times F_{1}+1.745 \times F_{2}+2.512 \times F_{3}+4.021 \times F_{4}+3.801 \times F_{5}}}(7)
$$

When the indexes of 3PL are removed from the model, the probability of default $W^{*}$.

\subsection{Results}

By Logistic Regression based on 60 SMEs, we divide $\mathrm{P}$ by 0.5 . When $\mathrm{P}>0.5$, it is considered that the enterprises will default; when $\mathrm{P}<0.5$, it is considered that the enterprises will not default. The confusion matrix of Logistic Regression is shown as Table 4. The indexes of 3PL and characteristics of pledge are excluded in Model 1. 
Table 4. Confusion matrix

Model 1 (excluding 3PL and pledged variables)

\begin{tabular}{|c|c|c|c|c|}
\hline \multirow{2}{*}{\multicolumn{2}{|c|}{$W^{*}$}} & \multicolumn{2}{|c|}{ Predicted } & \multirow{2}{*}{$\begin{array}{l}\text { Percentage } \\
\text { Correct }\end{array}$} \\
\hline & & 0 & 1 & \\
\hline \multirow{2}{*}{ Observed } & 0 & 31 & 9 & 77.5 \\
\hline & 1 & 3 & 17 & 85.0 \\
\hline \multicolumn{2}{|c|}{ Overall Percentage } & & & 80.0 \\
\hline \multicolumn{5}{|c|}{ Model 2 (including 3PL and pledged variables) } \\
\hline \multirow{2}{*}{\multicolumn{2}{|c|}{$W$}} & \multicolumn{2}{|c|}{ Predicted } & Percentage \\
\hline & & 0 & 1 & Correct \\
\hline \multirow{2}{*}{ Observed } & 0 & 37 & 3 & 92.5 \\
\hline & 1 & 2 & 18 & 90.0 \\
\hline \multicolumn{2}{|c|}{ Overall Percentage } & & & 91.6 \\
\hline
\end{tabular}

Compared with the results before and after the addition indexes of 3PL and pledges. Before the addition, the prediction accuracy is low and the overall percentage correct is $80.0 \%$, The probabilities of mistaking the good credit enterprises as poor credit enterprises is $22.5 \%$, which will cause the good credit enterprises with lost the opportunity of financing. After adding the indexes of 3PL and pledge, the accuracy of prediction is greatly improved. The results show that the credit risk assessment system for the financing mode of FTW can predict the default risk of enterprises accurately.

\section{CONCLUSION}

Taking 60 manufacturing listed companies (included $20 \mathrm{ST}$ and *ST companies) as samples, the principal component analysis method is used to extract five principal components: the solvency and operation ability of SMEs, the development ability and profitability of SMEs, the financial ability of 3PL enterprises, the size and market position of 3PL enterprises and the characteristics of pledges. In addition, Logistic Regression Analysis is carried out on whether SMEs default. The result shows that the principal components of 3PL enterprises and pledges are of great significance in the equation, indicating that 3PL enterprises have an important impact on the credit risk assessment of the FTW financing. Conclusions can be drawn from the results that the accurate prediction of whether the enterprise will default can be made through the credit risk assessment system of the FTW financing. Adding the indexes of 3PL enterprises and pledges can improve the accuracy of the prediction. Commercial banks can evaluate the default probability and credit risk of SMEs more accurately by evaluating 3PL enterprises and pledges, and reduce the potential risk significantly.

\section{ACKNOWLEDGMENTS}

This work was supported by Guangdong Province Philosophy and Social Sciences "13th Five-Year Plan"
2016 Disciplinary Co-construction Project (GD16XGL32).

\section{REFERENCES}

[1] L. Klapper, MR. Bakker, A. Claster, T. Glaeessner, D. Vittas. The Role of "Reverse Factoring" in Supplier Financing of Small and Medium Sized Enterprises. The World Bank, 2005, pp. 1-32. DOI: http://dx.doi.org/

[2] Luo q., Zhu D.L., Chen B.M. A Third-party Logistics Service Innovaton: Financing Warehouse and Its Operation Model. China Business and Market, 2002, 02:11-14.

[3] Xiong X., Ma J., Zhao W.J., Wang X.Y., Zhang J. Credit Risk Analysis of Supply Chain Finance. Nankai Business Review, 2009, 12: 92-98.

[4] Hu H., Zhang L., Zhang D.h., Chen L. Research on Finance Credit Risk Assessment of Supply Chain Based on SVM. Soft Science, 2011， 25:26-30,36.

[5] Shao L.T., Zhang M., Cheng X. Research on the Financing Mode of Agricultural Production Enterprises in China Based on the Perspective of Supply Chain Finance. Journal of Chinese Agricultural Mechanization, 2021, 42: 227-236. 